\title{
A Study on Social Competence of Secondary School Students Residing in Juvenile Homes
}

\author{
Shylaja C V*
}

\section{Abstract}

The present study examines the social competence of secondary school students residing in Juvenile homes. Studies report that the residents of Juvenile homes are deficient in social adaptation skills. This could be due to lack of resources and support. Schools within Juvenile homes could provide resources to develop social competence skills beneficial for their personal and social development. The study used surveys to measure the level of social competence of the secondary school students residing in the Juvenile homes of Kerala with the sub-samples based on gender, locality, and type of institution. The study reports significant differences in social competence between boys and girls, urban and rural population, and government, aided, and private residents of Juvenile homes.

Keywords: Social competence, Juvenile home, Gender, Social competence

\section{Introduction}

Traditionally, social competence is defined as a complex system of social abilities, habits and skills, and knowledge (Brown, Odom \& McConnel, 2008). Social competence is an umbrella term for social, emotional, cognitive, and behavioural skills as well as

* Manonmaniam Sundaranar University, Tirunelveli, Tamilnadu, India; shylajacv.scv@gmail.com 
motivational and expectancy sets needed for successful social adaptation. Social competence is also seen as an ability to accept another's perspectives pertaining to a situation, to learn from previous experiences, and to apply those to the changes in social interactions. Social competence also denotes additional constructs such as social skills, social communication, and interpersonal communication. Education is a powerful instrument for the inculcation of values and attitudes in children. It aims at improving self-worth and maintaining personal dignity, thereby improving social competence among children. Our educational system focusses on the overall development and strives to identify factors which can promote better personal and social development. In India, individuals below the age of eighteen found culpable of breaking the law are transferred to Govt. Children's Home or Juvenile homes. The inmates of Juvenile homes are mostly wandering children or 'waifs', who are disciplined for petty nuisances and thefts. They are individuals who might have issues of adjustment with the societal norms and therefore, engage in law violations. The cut and thrust of family life, poverty, quarrel, rejection, death of parents, school hardships and so forth denies them their fundamental needs. Laws enacted half-heartedly are inadequate to bring them to the desirable channels.

The present study uses survey method on a sample size of 340 secondary school students residing in Juvenile homes to study their social competence. Students studying in both government and private schools were included in the sample.

\section{Objectives of the study}

To measure the social competence among secondary school students residing in Juvenile homes, the investigator conducted the present study based on the following objectives.

1. To evaluate the social competence levels of secondary school students residing in Juvenile homes

2. To find out the difference in social competence between boys and girls 
3. To find out the difference in social competence between rural and urban secondary school students residing in Juvenile homes

4. To find out the difference in social competence between government and private secondary school students residing in Juvenile homes

\section{Hypotheses of the study}

To achieve the objectives of the present study, the researcher formulated the following hypotheses for testing. They were presented in null form.

a) There is no significant difference in social competence between boys and girls residing in Juvenile homes.

b) There is no significant difference in social competence between rural and urban secondary school students residing in Juvenile homes.

c) There is no significant difference in social competence between government and private students residing in Juvenile homes.

\section{Methodology}

The method used for collecting the data was the survey method.

\subsection{Sample}

The study was carried out on a sample of 340 secondary school students residing in the Juvenile homes of Kerala. The sample included 121 boys and 119 girls from Juvenile homes of Kerala.

\subsection{Tool used}

To measure the awareness of social competence of the secondary school students residing in Juvenile homes, a Social Competence Scale, developed by the investigator with the guidance of her research supervisor, was employed. The scale contains 86 items covering the various aspects of social competence like social skills, empathy and so forth. 


\subsection{Analysis and interpretation of data}

The variables of the present study were the social competence of secondary school students residing in Juvenile homes, difference in the social competence based on their gender, locality of the institution, and type of the institution. The hypotheses were tested and results are presented. The implications of the results are analysed in relation to the problem of the study, after each hypothesis is tested.

\subsubsection{Social competence-gender wise analysis}

The sample of the present study includes 121 boys and 119 girls from secondary school residing in Juvenile homes. The difference in the mean scores of boys and girls sample for the social competence scale was tested by using the following hypothesis.

Hypothesis-1

There is no significant difference between boys and girls in the social competence.

The above hypothesis was tested by using t-test and interpreted below. The result of $\mathrm{t}$-test is presented in the table.1 given below.

Table 1 Mean, Standard Deviation, and computed t-value of scores in social competence based on Gender.

\begin{tabular}{llrlll}
\hline \multicolumn{2}{c}{ Variable Measured } & N & Mean & S.D & t-value \\
& Boys & 121 & 49.86777 & 24.57368 & \\
Gender & Girls & 119 & 60.03361 & 30.30157 & $2.856^{*}$ \\
\hline
\end{tabular}

*Significant at 0.05 level of significance.

The obtained t-value 2.856 for boys and girls in social competence is greater than that of the table value and is significant at 0.05 level of significance. The null hypothesis formulated for testing was that there is no significant difference between boys and girls in social competence. On the basis of our analysis, the null hypothesis is rejected. There is a significant difference between boys and girls with regard to the social competence.

Further, when the means were compared it was found that the girls scored higher than the boys. This confirms that girl students 
residing in Juvenile homes have higher level of social competence than boy students.

\subsubsection{Social competence scale - locality wise analysis}

The sample of the present study includes 168 rural students and 72 urban students. The difference in the mean scores of rural and urban students sample for the social competence was tested by using the following hypothesis.

Hypothesis-2

There is no significant difference between rural and urban students in social competence.

The above hypothesis was tested by using t-test and interpreted below. The result of $t$-test is presented in the table- 2 .

Table 2: Mean, Standard Deviation, and computed t-value of scores in social competence based on locality of the school.

\begin{tabular}{rrrrrr}
\hline \multicolumn{2}{c}{ Variable Measured } & \multicolumn{1}{l}{ N } & Mean & S.D & t-value \\
\hline \multirow{2}{*}{ Locality } & Rural & 168 & 51.22314 & 26.96216 & \\
& Urban & 72 & 61.76471 & 27.21811 & $3.013^{* *}$ \\
\hline
\end{tabular}

**Significant at 0.01 level of significance.

The obtained t-value 3.013 for rural and urban students at secondary school is greater than that of the table value and is significant at 0.01 level of significance. The null hypothesis is rejected. There is a significant difference between rural and urban students with regard to the social competence.

Further, when the means were compared it was found that the urban students scored higher than the rural students. This confirms that urban students have a high level of social competence than the rural students.

\subsubsection{Social competence - type of school wise analysis}

The sample of the present study includes 117 private and 123 government school students. The difference in the mean scores of government and private school sample for the social competence was tested using the following hypothesis. 


\section{Hypothesis-3}

There is no significant difference between government and private students in the social competence. The above hypothesis was tested by using t-test and interpreted below. The result of $t$-test is presented in the table-3.

Table 3: Mean, Standard Deviation, and computed t-value of scores in social competence based on Type of the school.

\begin{tabular}{lccccc}
\hline \multicolumn{2}{c}{ Variable Measured } & N & Mean & S.D & t-value \\
\hline Type of & Private & 117 & 51.47107 & 27.08661 & \\
School & Government & 123 & 61.46218 & 27.34147 & $2.843^{* *}$ \\
\hline
\end{tabular}

**Significant at 0.01 level of significance.

The obtained $t$-value 2.843 for the private and government students at secondary school is greater than that of the table value and is significant at 0.01 level of significance. The null hypothesis formulated for testing, there is no significant difference between government and private students in social competence, is rejected. Government and private students do differ significantly with regard to the social competence.

Further, when the means were compared it was found that the government students scored higher than the private students. This confirms that government students experiences a high level of social competence than that of the private students.

\subsection{Major results of the study}

The major findings of the present study are as follows:

There is a significant difference between boys and girls with regard to their social competency. The girl students residing in Juvenile homes have a higher level of social competency than the boy students.

There is a significant difference between rural and urban students with regard to their social competence. Urban students have a high level of social competence than the rural students.

There is a significant difference between government and private students with regard to their social competency. Government 
students experience a greater level of social competency than the private students.

\section{Conclusion}

Social competence of the secondary school students residing in Juvenile homes needs to be improved. There are differences between boys and girls in social competence and the girls exhibit a higher level of social competency. The care and concern received by the girl students in their family and schools may be the reason for the same. This study strongly recommends that boy students residing in Juvenile homes should be given more chances to utilise the library, opportunities to engage in social interactions and group activities, and thereby improve their social competency. Rural and urban secondary school students also differ in their social competence. The locality of the institution also influences the social competence of the secondary school students residing in Juvenile homes. Urban students have shown a higher social competency. Government school students residing in Juvenile homes have shown higher level of social competence than that of the private school students. This could be a response to the sufficient opportunities to make their own decisions and the better facilities and guidance from the authorities concerned. Moreover, they get sufficient help and funds from the government sector and support from the higher authorities. They are more aware of the opportunities and resources which could aid their development and that of the institution.

\section{References}

Baumeister, R. F., Campbell, J. D., Krueger, J. I., Vohs, K. D. (2003). Does high self-esteem cause better performance, interpersonal success, happiness, or healthier lifestyles?. Psychological Science in the Public Interest, 4(1), 1-44.

Bono, J. E., \& Judge, T. A. (2003). Core self-evaluations: A review of the trait and its role in job satisfaction and job performance. European Journal of Personality, 17(1), S5-S18.

Dormann, C., Fay, D., Zapf, D., \& Frese, M. (2006). A State-Trait Analysis of Job Satisfaction: On the Effect of Core Self-Evaluations. Applied Psychology: an International Review, 55(1), 27-51. 
Hewitt, J. P. (2009). Oxford handbook of Positive Psychology. Oxford University Press.

Judge, T.A., Locke, E.A., Durham, C.C. \& Kluger, A.N. (1998). Dispositional effects on job and life satisfaction: The role of core evaluations. Journal of Applied Psychology, 83(1), 17-34.

Koul, L. (2004). Methodology of Educational Research. New Delhi: Vikas Publishing.

Marsh, H.W. (1990). Causal ordering of academic self-concept and academic achievement: A multiwave, longitudinal path analysis. Journal of Educational Psychology, 82(4), 646-656.

Orth, U., \& Robbins, R.W. (2014). The development of self-esteem. Current Directions in Psychological Science, 23(5), 381-387.

Smith, E.R., \& Mackie, D.M. (2007). Social Psychology (3rd ed.). Hove, England: Psychology Press/Taylor \& Francis (UK). 